\title{
Morpho-physiological characteristics of the strength and stretching exercises according to their interdependence and interaction
}

\begin{abstract}
Nowadays people's interest in physical training has increased. Particularly popular are fitness strength trainings. The effectiveness of fitness training affects the results of those engaged in physical exercises. In this aspect, the problem of the mutual influence of strength and stretching exercises is investigated. In the article morph-physiological description of power exercises and exercises is presented on a stretch. The urgent and moved aside effects of these types of exercises are certain, and their interdependence. As a result of the study of special literature, the fast and late effects of the studied exercises were determined.
\end{abstract}

Volume 4 Issue 5 - 2019

Aftimichuk $\mathrm{O}$

State University of Physical Education and Sports, Moldova

Correspondence: Aftimichuk O, State University of Physical Education and Sports, Moldova, Email aftolig@mail.ru

Received: September 26, 2019 | Published: October 14, 2019

Keywords: force, flexibility, exercises, fitness training, stretching, morphological description, fast and late effects

\section{Introduction}

Physical exercises are the only way to keep "a good shape", even optimal, of the main functions, with the condition to do not interrupt them, because the state of their practice immediately leads to the disappearance of the effects obtained until then. Sanogenetic effects fully reward this effort. Effects of physical culture: on the cardiovascular, respiratory and muscular apparatus; they are the most important. The value of physical exercises for the heart, lungs and muscles is very important through systematic physical effort.

Life expectancy increases by four years in people who regularly practice physical exercises, and if it is possible to maintain body weight at the ideal value, an additional two to eight years is added. ${ }^{1}$

It is not new to anyone, that physical exercise is a handy means of preventing illnesses, especially for those who have a predisposing factor to the modern lifestyle, characterized by stress, incorrect eating, sedentary lifestyle or various abuses.

Each of us wants to be permanently healthy, fit, to enjoy a life without illness and without physical, mental and other problems. After all, health is a personal choice. Today we see people of all ages running, cycling or rolling, swimming or training in the aerobic, fitness gyms.

Particularly important is the co-interest of practitioners in performing physical exercises. An essential factor is the correct distribution of the uploads at every lesson for each practitioner. At the same time, it is necessary to coordinate the succession of different objectives of the lessons. The improvement of the human condition comes in the form of a complex of exercises, where some exercises can be the help of other exercises. ${ }^{2}$ This ripple can be adjusted by choosing the optimum load in weekly cycles, as well as in any other long-lasting cycles.

These rules refer to all types of physical exercises, including those for the development of strength and elasticity. In the training of strength sports tests these types of exercises are interdependent in the process of their development. The methodological peculiarities of the training of the fitness-training consist of the combination of the work with strength character and the exercises of different orientations, as well as of the stretching exercises. ${ }^{3,4}$

The aim of this paper was to justify the need to perform stretching exercises in a strength training program.

\section{Materials and methods}

The optimal level of strength and endurance development is an important component of fitness. The development of fitness represents the tendency to achieve the goals of the physical culture and the maintenance process of the different population groups. To a large extent it serves the cause of the elaboration and creation of new motor activity tests, unifying in the group of fitness programs with the strength steering. The complex of the specialized exercises is applied in fitness with the aim of forming the body beautiful and proportional, developing the motor qualities and increasing the possible functional level of the body.

The methodological peculiarities of the design of the fitness lessons consist of the combination of the exercises with strength character and those oriented to the development of the aerobic capacities, as well as of the stretching.

It is believed that force and flexibility are antagonistic physical qualities. However, the practice of physical training shows that without the development of one, further improvement of the other will not be realized.

In this connection, theoretical research methods were used: analysis of specialized literature in such areas as: theory and methods of physical education, sports training, morphophysiology, biochemistry, psychophysiology, etc.; generalization of the data of the studied materials; table method for differentiated synthesis of literature data. 


\section{Results and discussion}

Studying the literature in the field of fitness, as well as the experience of the workout of the strength fitness trainers, we have established that force training improves health, strengthens the muscles and ligaments of the pelvis, improves the human figure. ${ }^{5}$

The neuro-muscular apparatus generates the mechanical force generation. We need to understand the difference between force training in sports and the health training.

The strength sports training solves the objectives of increasing the strength of the muscles applied to the exercises of concrete competition provided that the maximum result is reached.

Fitness-strength training is aimed at creating anabolic background in the human body, provided it has a healthy effect. At the same time, other objectives can be solved: strength development, increasing and decreasing body mass, decreasing fat reserves, improving posture, etc.

Appropriately there is a difference in the methodical aspect. For strength sports training, increasing muscle load and weight gain more than $60-70 \%$ of the maximum weight, it is used the high tempo of performing the strength exercises ${ }^{6,7}$ In fitness-strength training most exercises have a local character, the load is not higher than $40-60 \%$, the movements are performed without muscle relaxation, keeping the rule of continuing the approach "until refusal", that is until the offensive of the sensations of pain and the high mental load. ${ }^{8}$ The movements are executed slowly and smoothly. The basic purpose of these exercises is to accumulate the metabolic organism and the biologically active substances, which contribute to the improvement of health (Table 1).

Table I Fitness-strength training

\begin{tabular}{|c|c|c|c|}
\hline \multicolumn{4}{|c|}{ Effects } \\
\hline Fast & & Late & \\
\hline I. & $\begin{array}{l}\text { Activation of sympatho-adrenal systems takes place, which mobilizes } \\
\text { energy and plastic resources, including fat reserves }\end{array}$ & I. & $\begin{array}{l}\text { Increases the strength and endurance of the muscles, } \\
\text { the desired shape is formed }\end{array}$ \\
\hline 2. & $\begin{array}{l}\text { The pituitary-genital system (pituitary, adrenal cortex, genital glands) is } \\
\text { activated, which accelerates protein synthesis. }\end{array}$ & 2. & $\begin{array}{l}\text { Cardiovascular system, in particular, it refines the } \\
\text { vascular reactions, it is getting better the micro- } \\
\text { circulation }\end{array}$ \\
\hline 3. & $\begin{array}{l}\text { During the correct technical execution of the exercises the heart rate, } \\
\text { oxygen consumption and blood pressure increase insignificantly }\end{array}$ & 3. & The activity of the internal organs is normalized \\
\hline 4. & $\begin{array}{l}\text { In the blood, muscle and other tissues are accumulated and stored for } \\
\text { a long time hormones, neurotransmitters, enzymes, the metabolism } \\
\text { improves }\end{array}$ & 4. & $\begin{array}{l}\text { The long-term mental and neuromuscular relaxation } \\
\text { is observed }\end{array}$ \\
\hline 5. & $\begin{array}{l}\text { The proper execution of exercises increases neurogenic and } \\
\text { mechanical positive influence on the internal organs }\end{array}$ & 5. & Cold resistance develops \\
\hline & & 6. & Personality psychology is improving \\
\hline
\end{tabular}

Studying the lesson systems, which use the stretching exercises, we proposed an interdependence in the development of the strength qualities from the development of the flexibility possibilities of the musculoskeletal system.

Flexibility is the ability of the joints to perform the movements with the maximum amplitude for them. First, this quality depends on the elasticity of the muscles, which are united in the joints. If the muscles and tissues that are close together have a high degree of elasticity, then the joints, corresponding to them, are capable of performing movements with the maximum amplitude. ${ }^{9}$ If the muscles are tense, the amplitude of the movements in the joints becomes tense, and even if the muscles are usually long enough to perform the movements with the maximum amplitude, their elasticity is limited by the conditioned myotatic reflex.

Apart from muscle elasticity, flexibility depends on the tension of the ligaments, which lead to joint mobility and muscle strength. In order to sustainably maintain the joint in the required position, the ligaments must be tightened to a certain degree. Highly charged ligaments limit the amplitude of movement in the joints.

Muscle strength must increase in parallel with the development of flexibility. ${ }^{10}$ Muscles, which do not have sufficiently developed strength and are preparing for stretching, lead to trauma of joints and ligaments. At one time, by developing muscular strength and flexibility, we train muscles, which are able to overcome high load and execute movements with maximum amplitude.

The high flexibility gives us harmony, efficiency and ease of movement. It ensures the effective use of the natural mechanics of the body, possessing to perform the movements without obstacles. Due to these, the athletes get the opportunity to execute the movements with the maximum amplitude, while developing the maximum speed and effort. ${ }^{11}$

In order for the movement to be made maximally strong, the muscles from the beginning must be fully straightened, and then fully stretched. If human has short muscles, the potential for strength creation is essentially below.

The insufficient mobility in the joints can be limited by the manifestation of the strength qualities. ${ }^{12}$ During stretching exercises, the main effects are muscles, their shells, fascia, tendons, ligaments and joint bags of joints. This group may be referred to as the connective tissue formation (CTF). CTF consist of two types of fibers: collagen and elastin, which contains a structure of different ratios on which the elastic properties of CTF depend. 
The construction of collagen and elastin is similar, because they consist of tissue bundles. However, in the tissue collagen they are bonded to the hydrogen bonds, and in the elastin the same bundles are joined in the placed structure. As the age of immobilization of the joints changes, the chemical composition of the CTF takes place, the calcination and dehydration. This leads to the increase of the number of hydrogen bonds, and consequently to the decrease of the elastic properties..$^{13,14}$

Improving the CTF range of muscles and joints is possible under conditions of regular stretching. However, the reflex tightening of the muscle fibers disturbs the CTF stretch, leading to pain sensations. The weakening of the reflex loads of the muscles can achieve the following procedures: ${ }^{15,16}$
1. Maintaining the muscles stretched for a long time;

2. At the moment of stretching it is necessary to tighten the antagonist muscle;

3. Tightening in a row and relaxing the muscles in the stretching state;

4. Vibration of muscles during stretching;

5. Spontaneous efforts when relax the stretched muscles.

It can be observed two aspects of stretching: the development of flexibility and the receiving of the healthy effect from the activation of different mechanisms of influence in the body (Table 2).

Table 2 Stretching fitness training

\begin{tabular}{l} 
Effects \\
\hline Fast \\
$\begin{array}{l}\text { Intensive proprioceptive impulse leads to an increase in the } \\
\text { tone below the bark of the brain, which causes a complex } \\
\text { of reactions in the body, similar to those, which take place } \\
\text { during the execution of different dynamic exercises and } \\
\text { massage }\end{array}$ \\
$\begin{array}{l}\text { Local irritation of the neuronal endings contributes to } \\
\text { the activation of the metabolic processes of the stretched } \\
\text { muscles and connective tissues } \\
\text { The mobilization of fat reserves will contribute to the } \\
\text { combination of stretching under pain management } \\
\text { conditions, to strength exercises }\end{array}$ \\
$\begin{array}{l}\text { Alternating the load and stretching the muscles } \\
\text { in stretching can be considered as training for the } \\
\text { spontaneous adjustment of the muscle load and the } \\
\text { spontaneous relaxation of the muscles, in other words - as } \\
\text { an improvement of the coordination skills }\end{array}$
\end{tabular}

Late

Increased elasticity of collagen and percentage of elastin content in CTF of muscles and joints, which contributes to the decrease of calcium

Removal of muscle "fixators"

Reduction and clearance of muscle pain after loading and even trauma during rehabilitation

4. Prophylaxis of hypo dynamics in older people

5. Normalization of body mass and composition
Stretching exercises can be performed at all stages of the workout. The unwanted decrease in the movement of the tensed muscles during the exercises can be overcome by three methodical factors:

i. The successive use of strength and stretching exercises.

ii. The use of strength and stretching exercises during one training.

iii. The same time development of force and flexibility in the process of strength exercises.

\section{Conclusion}

The approach to the problem of the efficiency of the fitness training process must be based on the theory and practice of applying the contents of the current fitness tests, which positively influences the increase of the interests and motivations of those who engage in physical exercises.

Raising the level of flexibility development contributes to improving the strength capacities of those who engage in fitness.

\section{Acknowledgements}

None.

\section{Conflicts of interest}

The authors declare that there is no conflict of interest.

\section{References}

1. Prokhorov BB, Gorshkova IV, Shmakov DI. Public health and economics. Moscow: MAKS Press; 2007.

2. Malina R. Physical activity and health of youth. Constanta: Ovidius University Annals, Series Physical Education and Sport/Science, Movement and Health. 2010.

3. Donche D. FF trainer certification guide. USA: Fatal Fitness. 2008

4. FurmanovAG, Iuspa MB. Wellness physical culture. Minsk: Theseus. 2003.

5. Aftimichuk OE. Theory and methodology of power fitness. Textbook. Chisinau: Valinex. 2018

6. Abernethy P, Wilson G, Logan P. Strength and power assessment. Sports Medicine. 1995;19(6):401-417.

7. Dragnea A. Measurement and evaluation in motor activities. Pitești. University of Pitesti. 2002 
8. Porter R, WhelanJ. Editors. Human muscle fatigue: physiological mechanisms. London: Pitman Medical. 1981.

9. Alter MJ. Science of flexibility. 3rd ed. Human Kinetics. 2004.

10. Oswald C, Bacso S. Stretching for fitness, health \& performance: the complete handbook for all ages \& fitness levels. Toledo, $\mathrm{OH}$, Published by Sterling. USA; 2003.

11. Beedle B. Flexibility characteristics among athletes who weight train. $J$ Applied Sports Science Research. 1991;5:150-154.

12. Kokkonen J, Nelson AG, Cornwell A, et al. Acute muscle stretching inhibits maximal strength performance. Research Quarterly for Exercise and Sport. 1998;69:411-415.
13. Demeter A. Bazele fiziologice și biochimice ale calităţilor fizice. Bucureşti: Sport-Turism; 1981

14. Zoladz JA. Muscle and exercise physiology. Kraków: Academic Press. 2019.

15. Dragnea A. Teoria şi metodica dezvoltării capacităţilor motrice. Compendiu. MTS. Bucureşti. 1991.

16. Wilmore JH, Costill DL. Training for sport and activity: the physiological basis of the conditioning process. Human Kinetics Publishers. 1993. 